

\title{
FARINHA DE MORINGA OLEÍFERA LAM. COMO FONTE DE SUPLEMENTAÇÃO EM CREPIOCAS
}

\author{
Apresentação: Pôster
}

\begin{abstract}
Andreza Agda Dantas Silva ${ }^{1}$; Camila Lima do Nascimento ${ }^{2}$; Rafael Wylles da Silva Araújo ${ }^{3}$; George Henrique Camêlo Guimarães ${ }^{4}$; Jeane Medeiros Martins de Araújo ${ }^{5}$
\end{abstract}

\section{Introdução}

A Moringa Oleífera Lam (MO) é uma planta pertencente à família Moringaceae, nativa do norte da Índia, é uma hortaliça perene e arbórea, com aproximadamente cinco metros de altura, tronco delgado, folhas compostas, flores numerosas e frutos longos, parecidos com uma vagem e que contém muitas sementes (MADRONA et al., 2011). Praticamente todas as suas partes possuem valor alimentício (folhas, flores, vagens e sementes) e medicinal (todas as partes da planta).

Os conteúdos proteico, vitamínico e mineral são bastante significativos, sendo considerado um dos melhores vegetais perenes. Com forte potencial alimentício a moringa vem se inserido aos poucos na dieta ocidental como uma alternativa de suplemento proteico e vitamínico. Diferentemente das plantas nativas do semiárido, a Moringa não perde suas folhas no período de seca, podendo se tornar uma alternativa nutritiva para grande parte do território brasileiro. Além da resistência à seca, a moringa exige pouca adubação, boa tolerância às pragas e doenças, além de ser utilizada como cerca viva e quebra-vento em algumas regiões (BAPTISTA et al., 2012).

Sob esta perspectiva, justifica-se a necessidade de buscar novas alternativas que promovam o uso deste vegetal em suas variadas formas de modo a complementar nutricionalmente a dieta de um indivíduo. Assim, este estudo objetivou avaliar a aceitação de crepiocas suplementadas elaboradas com a farinha Moringa oleífera Lam. como alternativa de aporte proteico em sua composição.

\section{Fundamentação Teórica}

\footnotetext{
${ }^{1}$ Tecnologia em Agroecologia, IFPB campus Picuí, andrezaagda25@gmail.com;

${ }^{2}$ Tecnologia em Agroecologia, IFPB campus Picuí, camilapb.lima@yahoo.com.br;

${ }^{3}$ Tecnologia em Agroecologia, IFPB campus Picuí, rafaelwylles1@gmail.com;

${ }^{4}$ IFPB campus Picuí, george.guimaraes@ifpb.edu.br;

${ }^{5}$ ngenheira Agrônoma; Professora do CST em Agroecologia IFPB, Picuí, jemartins@ @otmail.es.
} 
Atualmente a Moringa é encontrada em diversos países trópicos, com desenvolvimento em climas úmidos ou quentes podendo sobreviver em solos pouco férteis e secos, além de possuir crescimento rápido. Suas sementes são usadas no tratamento de purificação da água, por floculação e sedimentação, o óleo contido na semente pode ser usado para cozinhar e confeccionar sabão, sendo utilizado também na indústria farmacêutica e cosmética. As sementes, folhas e flores são consumidas como legumes em alguns países, as vagens verdes cozidas e sementes maduras (torradas) são ingeridas como verduras. No Brasil tem-se investido em diversos programas de divulgação e plantio e utilização da moringa devido o seu potencial nutricional. Essa espécie apresenta quantidades significativas de cálcio, ferro, cobre, proteínas, fósforo, potássio, vitaminas A, B e C e possui todos os aminoácidos essenciais. Por esse motivo, algumas escolas na região de Minas Gerais tem adicionado a moringa na alimentação escolar, na região Norte e Nordeste, o pó das folhas é bastante utilizado para enriquecer sucos, bolos, arroz, entre outras preparações.

\section{Metodologia}

A pesquisa possui caráter qualitativo e se constitui na elaboração da crepioca suplementada com farinha das folhas de Moringa oleífera. A realização do estudo se deu no laboratório de beneficiamento vegetal do Instituto Federal de Educação, Ciência e Tecnologia da Paraíba campus Picuí (IFPB). Dois tipos de crepioca foram preparadas, convencional e suplementada, que foi adicionada de farinha da moringa (5\%). Para a elaboração da crepioca convencional, utilizou-se 40 gramas de massa de mandioca peneirada em peneira doméstica plástica, adicionada de 1 ovo inteiro, os ingredientes foram homogeneizados com o auxílio de garfo em recipiente de vidro, de modo a formar uma massa fina de coloração amarelada e sem grumos. Para elaboração da crepioca suplementada com moringa, repetiu-se o mesmo procedimento da convencional, porém acrescentou-se 5\% (2 gramas) da farinha à mistura e, em seguida, homogeneizou-se. As massas foram levadas a fogo brando de $85^{\circ} \mathrm{C}$ por cerca de 3 minutos em frigideira antiaderente. Em seguida, recheou-se e enrolou-se ambas as massas com frango desfiado temperado anteriormente a preparação das mesmas. Para análise sensorial das amostras, utilizou-se escala hedônica de nove pontos (desgostei extremamente, desgostei muito, desgostei moderadamente, desgostei ligeiramente, indiferente, gostei ligeiramente, gostei moderadamente, gostei muito e gostei extremamente), por 17 avaliadores não treinados.

\section{Resultados e Discussões}


As amostras de crepioca com adição de pó das folhas da Moringa Oleífera Lam. foram avaliadas sensorialmente, por teste de aceitação, por 17 provadores não treinados, de ambos os sexos, entre professores e funcionários do IFPB campus Picuí-Pb. Diante dos resultados obtidos após análise sensorial das duas crepioca, 58,9\% dos avaliadores "Gostaram Muito" a crepioca convencional, contrapondo-se com e 35,2\% para a crepioca suplementada com o pó das folhas de moringa (Figura 1). Dos provadores, 17,7\% "Gostou extremamente" da crepioca suplementada e 23,6\% da crepioca convencional. Apenas 5,9\% dos provadores marcaram como "desgostei extremamente" a crepioca suplementada e 5,8\% se mostrou "Indiferente" em relação a crepioca convencional. A maioria dos provadores afirmou não perceber diferenças significativas no sabor e odor das amostras, no entanto, a aparência da amostra suplementada apresentou coloração esverdeada, o que pode ter causado menor aceitação pelos provadores.

Outros produtos são utilizados enriquecidos com a Moringa oleífera, em estudo realizado por Teixeira et al. (2013) com hambúrgueres adicionados do pó da folha de moringa, demonstraram que a adição de farinha de folhas de moringa não é uma alternativa viável em relação à atividade antioxidante, pois contribuiu significativamente para a oxidação lipídica.

Outro emprego do pó das folhas de Moringa oleífera Lam pode ser observado no trabalho de Oliveira et al (2009). O objetivo foi determinar e comparar a aceitabilidade de três sorvetes elaborados com extrato de soja (leite de soja) e enriquecidos com Moringa de diferentes sabores. Os produtos também obtiveram boas notas de aceitação, contudo, quando enriquecidos com moringa, a aceitação foi maior quando usado em combinação com algum sabor diferente.

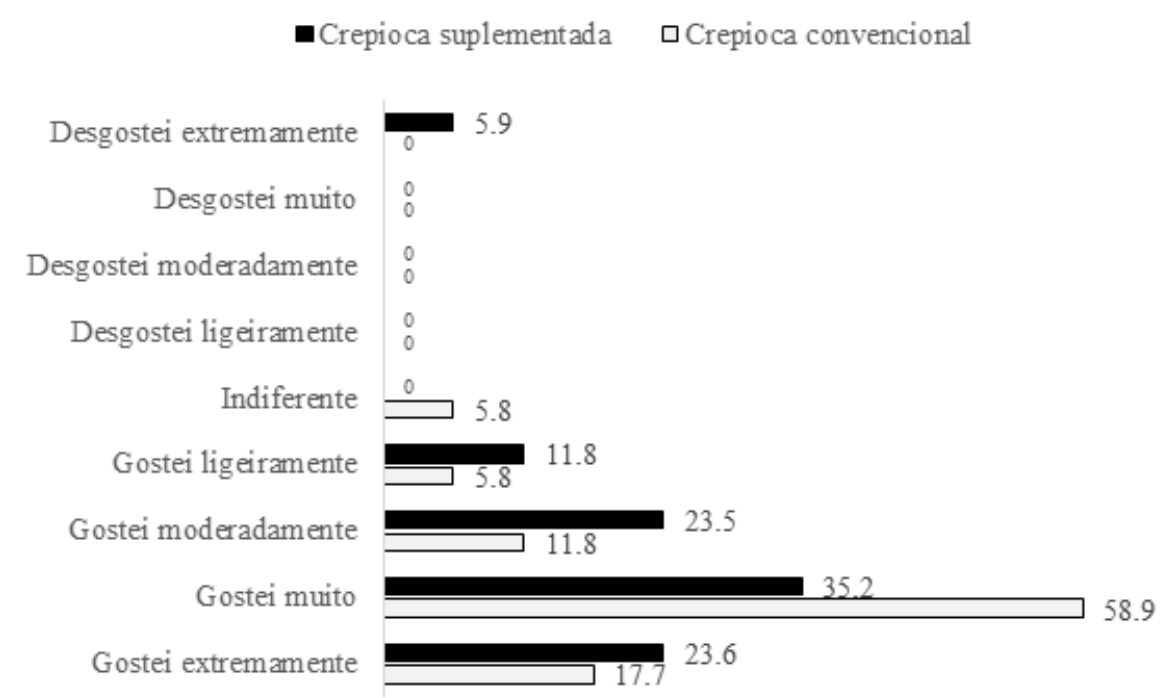

Figura 1: Análise sensorial de crepioca convencional e suplementada com Moringa oleífera Lam. 
A adição do pó proveniente das folhas secas da Moringa Oleífera Lam. também já foi realizada por Brito e Teixeira (2009), que teve como objetivo avaliar a aceitabilidade do pão francês fortificado com o pó da Moringa. As amostras apresentaram aceitabilidade satisfatória em relação aos atributos avaliados, e os valores das médias para aroma, cor e textura apresentaram-se entre os termos 'indiferente' e 'gostei moderadamente'. O pão mais aceito foi o que continha menor quantidade do pó.

\section{Conclusões}

A Moringa Oleífera é uma espécie com grande potencialidade para utilização e exploração, principalmente como fonte de enriquecimento alimentar. Estudos preliminares que avaliem a introdução desta planta em produtos alimentícios, verificando a aceitação são de relevância por nortear pesquisas futuras, de forma a contribuir com o avanço no estudo de espécies alternativas para melhoria e enriquecimento alimentar. Neste trabalho foi avaliado a aceitação de crepiocas enriquecidas e foi observado menor aceitação quando comparados com crepiocas convencionais, possivelmente pela pequena mudança na coloração, como mencionado por alguns avaliadores. Este tipo de resultado impulsiona pesquisas futuras, com intuído de caracterizar sensorialmente novos produtos alimentícios enriquecidos com Moringa Oleífera.

\section{Referências}

BAPTISTA, A. T. A.; SILVA, M. O.; BERGAMASCO, R.; VIEIRA, A. M. S. Avaliação físicoquímica e sensorial de biscoitos tipo cookies elaborados com folha de Moringa oleífera. $B$. CEPPA, Curitiba, v. 30, n. 1, p. 65-74, jan./jun. 2012.]

BRITO, T.M.L.P., TEIXEIRA, E.M.B.. ENCONTRO NACIONAL DE MORINGA, Aceitabilidade do pão francês enriquecido com pó da folha da Moringa oleífera Lam.; 02 a 04 de setembro de 2009, Aracaju - Sergipe. Caminhos do Campo; As muitas utilidades da moringa.

MADRONA, G. S.; BUENO, R. S.; SANTOS, P. H. C.; SCAPIM, M. R. S.; MONTEIRO, A. R. G.; CESTARI, L. A.; BERGAMASCO, R. Adição do pó da folha de moringa oleífera lam em sorvete. Revista Tecnológica, Edição Especial V Simpósio de Engenharia, Ciência e Tecnologia de Alimentos, pp. 63-67, 2011.

OLIVEIRA, I.C.; TEIXEIRA, E.M.B.; PEREIRA, L.A.. ENCONTRO NACIONAL DE MORINGA, Aceitabilidade de sorvetes elaborados com "leite" de soja e enriquecidos com pó de Moringa oleifera Lam. de diferentes sabores. 02 a 04 de setembro de 2009, Aracaju - Sergipe. RURAL. Moringa (Moringa oleifera Lam)

TEIXEIRA, E. M. B., et al., Caracterização de hambúrguer elaborado com farinha de folhas de Moringa (Moringa oleífera Lam.), Revista Sociedade Brasileira de Alimentação e. Nutrição, São Paulo, SP, v. 38, n. 3, p. 220-232, dez. 2013. 